\title{
Endoscopic full-thickness resection of colorectal lesions with the full-thickness resection device: clinical experience from two referral centers in Greece
}

\author{
Magdalini Velegraki ${ }^{a}$, Artemis Trikolab ${ }^{b}$ Konstantinos Vasiliadis ${ }^{b}$, Maria Fragaki ${ }^{a}$, Afroditi Mpitoulia \\ Ioannis Dimas a , Evangelos Voudoukis a, Elpida Giannikakic, Amalia Kapranou d , Athanasios Kordelas ${ }^{d}$, \\ Gerasimos Stefanidis $^{\mathbf{b}}$, Gregorios A. Paspatis ${ }^{\mathrm{a}}$
}

Venizeleion General Hospital, Heraklion, Crete; Athens Naval Hospital, Greece

Abstract

Department of a Gastroenterology, Venizeleion General Hospital, Heraklion, Crete (Magdalini Velegraki, Maria Fragaki, Afroditi Mpitouli, Ioannis Dimas, Evangelos Voudoukis, Gregorios A. Paspatis); ${ }^{\mathrm{b}}$ Gastroenterology, Athens Naval Hospital, Athens (Artemis Trikola, Konstantinos Vasiliadis, Gerasimos Stefanidis); 'Histopathology, Venizeleion General Hospital, Heraklion, Crete (Elpida Giannikaki); ${ }^{\mathrm{d}}$ Histopathology, Athens Naval Hospital, Athens (Amalia Kapranou, Athanasios Kordelas), Greece

Conflict of Interest: None

Correspondence to: Gregorios A. Paspatis, MD, PhD, Department of Gastroenterology, Venizeleion General Hospital, Knossou Avenue, 71409 Heraklion, Greece, e-mail address: gpaspatis@gmail.com

Received 18 February 2019; accepted 22 May 2019; published online 10 June 2019

DOI: https://doi.org/10.20524/aog.2019.0392

\section{Introduction}

Endoscopic mucosal resection (EMR) and endoscopic submucosal dissection (ESD) are well-established endoscopic techniques for the removal of colorectal lesions [1-4]. Both are based on separation of the mucosa/submucosa from the muscular layer by injection in the submucosal space. Nonetheless, in non-lifting colorectal lesions, EMR and ESD might not be technically feasible. Colorectal lesions located at difficult anatomic sites (e.g., appendiceal orifice, diverticulum) and subepithelial tumors are also difficult to treat using conventional endoscopic techniques, with an inherent risk of perforation or incomplete resection. Endoscopic full-thickness resection (EFTR) is an invasive treatment for lesions when EMR and ESD are not possible or available. The full-thickness resection device $\left(\right.$ FTRD $^{\circledR}$, Ovesco Endoscopy, Tübingen, Germany) allows single- 
step EFTR through an over-the-scope clip (OTSC), placed below the lesion prior to resection. The device was introduced into clinical practice for colorectal EFTR in September 2014 and has been described as feasible and efficacious in 3 large clinical studies (including 181, 114, and 48 patients respectively) [5-7] and 5 smaller retrospective studies [8-12]. To the best of our knowledge, this study presents the first Greek experience of the FTRD $^{\circledR}$ procedure, including patients from 2 referral centers. We aimed to evaluate the efficacy and safety of EFTR for colorectal lesions not amenable to EMR and ESD.

\section{Patients and methods}

This observational, retrospective study was conducted in 2 referral centers in Greece (Venizeleion General Hospital, Heraklion, and Athens Naval Hospital, Athens) from October 2015 through December 2018. We included patients with colorectal lesions not amenable to EMR or ESD who would otherwise have had to be treated surgically. Indications for EFTR were non-lifting colorectal adenomas (residual, recurrent, without previous treatment), adenomas at difficult anatomic locations (appendiceal orifice, diverticulum), suspected T1 adenocarcinomas with indication for endoscopic resection, and subepithelial tumors. Suspected early adenocarcinomas were treated with EFTR based on "low-risk" histopathologic features after initial polypectomy: absence of lymphovascular invasion, good/moderate differentiation grade, and submucosal infiltration $<1000 \mu \mathrm{m}$. These patients underwent a complete workup for colorectal cancer, including computed tomography (CT) scan of the abdomen for colonic lesions, and magnetic resonance imaging (MRI) for rectal lesions. Additionally, they were thoroughly informed about the possibility of undetected lymph node metastases $( \pm 5 \%)$. All cases with suspected T1 adenocarcinoma were discussed at multidisciplinary oncology meetings for further evaluation. Patient and lesion characteristics are displayed in Table 1. A complete diagnostic colonoscopy before $\mathrm{FTRD}^{\circledR}$ procedure was performed and all patients signed the informed consent form. Outcome parameters were:

a. Technical success: resection in one piece and macroscopically complete

b. $R 0$ resection: negative lateral and deep margins based on histological examination

c. EFTR-related adverse events: clinical complications including bleeding, appendicitis, post-polypectomy syndrome, abdominal pain, perforation, and enterocolonic fistula after EFTR of an adenoma involving the appendiceal orifice.

The severity of adverse events was graded according to the changes in the plan of care, as recommended by the American Society for Gastrointestinal Endoscopy [13]. Specifically, clinical complications that required unplanned hospital admission or prolongation of hospital stay for $\leq 3$ nights were considered as mild and those which required prolongation of stay for 4-10 nights, admission to the Intensive Care Unit (ICU) for 1 night, transfusion and/or repeat endoscopy were regarded as moderate. Adverse events that resulted in a prolongation of stay for $>10$ nights, ICU admission for $>1$ night and/or surgery were considered as severe.
Table 1 Patient and lesion characteristics $(\mathrm{n}=17)$

\begin{tabular}{|c|c|}
\hline Characteristic & Value \\
\hline \multicolumn{2}{|l|}{ Sex } \\
\hline Male & 10 \\
\hline Female & 7 \\
\hline Age, mean (range)/median, years & $59.7(40-82) / 66$ \\
\hline \multicolumn{2}{|l|}{ Indication for EFTR } \\
\hline - Difficult adenoma & 8 \\
\hline \multicolumn{2}{|l|}{$\begin{array}{l}\text { 1. Adenoma with negative lifting } \\
\text { sign (non-lifting adenoma) }\end{array}$} \\
\hline Residual adenoma & 5 \\
\hline Recurrent adenoma & - \\
\hline Non-lifting adenoma without prior treatment & 1 \\
\hline 2. Adenoma involving the appendiceal orifice & 2 \\
\hline $\begin{array}{l}\text { - T1 carcinoma with indication for endoscopic } \\
\text { resection }\end{array}$ & 3 \\
\hline 1. Resection margins $<1 \mathrm{~mm}$ & 1 \\
\hline 2. Suspected submucosal invasion & 1 \\
\hline 3. Non-surgical candidate & 1 \\
\hline - Subepithelial tumor & 6 \\
\hline \multicolumn{2}{|l|}{ Location of lesion } \\
\hline Cecum & 3 \\
\hline Ascending colon & - \\
\hline Transverse colon & 1 \\
\hline Descending colon & - \\
\hline Sigmoid & 7 \\
\hline Rectosigmoid colon & 4 \\
\hline Rectum & 2 \\
\hline $\begin{array}{l}\text { Maximum diameter of lesion, mean (range)/ } \\
\text { median, mm }\end{array}$ & $12.7(5-30) / 10$ \\
\hline
\end{tabular}

EFTR, endoscopic full-thickness resection

\section{EFTR procedure}

The selected patients were administered a "single shot" dose of prophylactic antibiotic treatment before EFTR and the procedure was performed under sedation with midazolam and pethidine. All procedures were performed with $\mathrm{CO}_{2}$ insufflation. The lesions were initially identified endoscopically with a standard colonoscope and were measured using an opened forceps. The resection margins were marked circumferentially using the marking probe that is part of the FTRD $^{\circledR}$ set. The FTRD ${ }^{\circledR}$ system was already mounted on another colonoscope. The EFTR device consists of a transparent cap, on which a $14 \mathrm{~mm}$ OTSC is preloaded, and an integrated $13 \mathrm{~mm}$ snare (Fig. 1). The identified lesion was grasped into the cap using the FTRD ${ }^{\circledR}$ grasper until the circumferential markings were visible. The clip was then released and the lesion was resected with the snare integrated in the system (Fig. 2). The resected specimen was extracted with the endoscope, which was then reintroduced to inspect the resection site. The total procedure time was measured from the first introduction of the colonoscope until its extraction after the inspection of the resection site. The time needed to reach the targeted lesion was measured from the introduction of the FTRD ${ }^{\circledR}$ and the time for resection was measured from reaching the lesion with the FTRD $^{\circledR}$ until resection was accomplished. All specimens were evaluated by a local histopathologist in each center. 


\section{Statistical analysis}

Data were recorded in a Microsoft Excel spreadsheet and analyzed using SPSS 10. Patient/lesion characteristics and EFTR-related adverse events were outlined descriptively. Categorical variables were tested using corrected $\chi^{2}$ or 2 -sided Fisher's exact tests for univariate comparisons, as appropriate. A P-value $<0.05$ was considered statistically significant.

\section{Results}

\section{Patient characteristics and indications for EFTR}

From October 2015 through December 2018, 17 consecutive patients ( 10 male, 7 female, mean age 59.7 years) underwent EFTR at two referral centers in Greece. As shown in Table 1, the resection sites were the cecum $(n=3)$, transverse colon $(n=1)$, sigmoid $(n=7)$, rectosigmoid colon $(n=4)$, and rectum $(n=2)$. Procedural data are shown in Table 2. The target lesion was reached with $\mathrm{FTRD}^{\circledR}$ in all patients. Technical success and R0 resection were achieved in 14 of 17 procedures (82.3\%). One resection was macroscopically incomplete because of the size of the lesion $(30 \mathrm{~mm})$. The patient was finally diagnosed with a lipoma and no further management

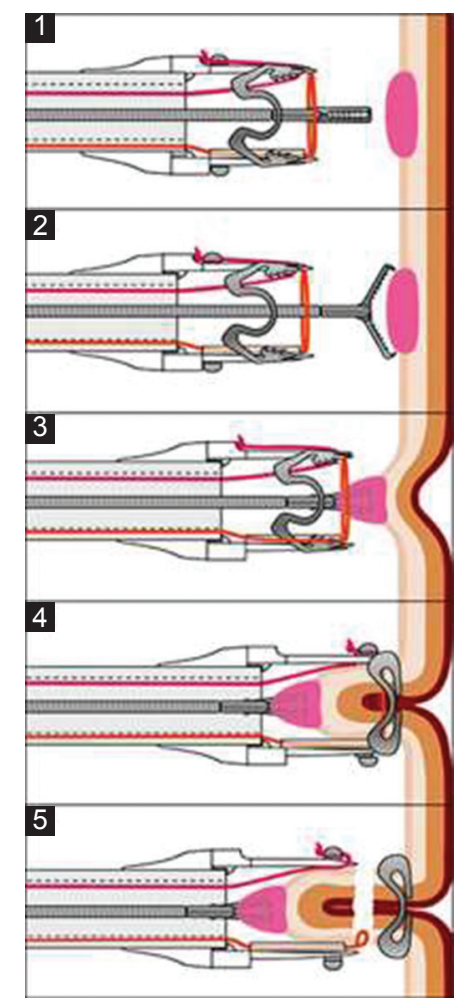

Figure 1 Schematic illustration of an $\mathrm{EFTR}^{\star}$ with FTRD ${ }^{\circledR}$ (www. ovesco.com). (1,2) Positioning on resection site with endoscope; (3) Grasping of marked tissue and drawing into cap with FTRD ${ }^{\circledR}$ grasper; (4) Application of the over-the-scope clip; (5) Snare closing and resection of tissue

${ }^{*}$ EFTR, endoscopic full-thickness resection; FTRD ${ }^{\circledR}$, full-thickness resection device was needed. In 2 other patients the target lesions could not be resected as it was not possible to draw the tissue into the cap. These lesions, located in the rectum and rectosigmoid transition, could not be moved far enough into the FTRD ${ }^{\circledR}$ cap, probably because of their location and severe scarring (post-radiation) of the site. The patients were treated surgically. A subgroup analysis concerning technical success and R0 resection is shown in Table 3.

The mean diameter of lesions prior to resection was 12.7 (range 5-30) $\mathrm{mm}$. Histopathology revealed R0 resection in 14 specimens (82.3\%). The majority of patients $(82.3 \%, 14 / 17)$ remained hospitalized for 1-3 post-intervention days and were monitored for clinical complications. In 3 patients (17.6\%) hospitalization was prolonged owing to procedure-related adverse events.

\section{Subgroup of difficult adenomas $(n=8)$}

This subgroup included 6 adenomas with negative lifting sign (residual adenoma after initial polypectomy $\mathrm{n}=5$, non-lifting adenoma without prior endoscopic treatment $n=1$ ), and 2 cases of adenomas involving the appendiceal orifice. Resection sites were the following: cecum $(n=2)$, transverse colon $(n=1)$, sigmoid $(n=3)$, rectosigmoid colon $(n=1)$, and rectum $(n=1)$. Technical success and R0 resection were achieved in 7 of 8 cases (87.5\%). The median lesion size was 14 (range 10-20) mm. Final histology showed in situ adenocarcinoma $(\mathrm{n}=1)$, adenoma with low-grade dysplasia $(n=4)$, adenoma with high-grade dysplasia $(n=1)$, and scar tissue $(n=1)$. In the case of the non-lifting adenoma without previous treatment, located in the rectum, EFTR was not feasible since the lesion could not be drawn sufficiently into the cap. The failure was attributed to the rectal wall (less mobile than colonic) and severe scarring of the site due to radiation therapy provided for prostate cancer years before. The patient was referred for surgery.

\section{Subgroup of adenocarcinomas $(n=3)$}

Three patients underwent EFTR for biopsy-proven adenocarcinomas. Lesions were located in the sigmoid $(\mathrm{n}=1)$ and rectosigmoid colon $(\mathrm{n}=2)$. The median diameter was 10 (range 5-15) mm. Technical success and R0 resection rate was $66.6 \%$. One patient had been diagnosed with adenocarcinoma of good differentiation grade; the tumor was completely resected

Table 2 Procedural data

\begin{tabular}{lc}
\hline Characteristic & Value \\
\hline Median procedure time, min & Mean (range)/median \\
Total & $36.9(10-90) / 30$ \\
$\begin{array}{l}\text { Time needed to reach the lesion with } \\
\text { FTRD }^{\circledR}\end{array}$ & $12.8(2-45) / 10$ \\
Time for resection & $7.42(3-20) / 5$ \\
Target lesion reached with FTRD & , n (\%) \\
Technical success, n (\%) & $17 / 17(100)$ \\
R0 resection, n (\%) & $14 / 17(82.3)$ \\
\hline
\end{tabular}

FTRD $^{\circledR}$, full-thickness resection device 
Table 3 Subgroup analysis concerning technical success and R0 resection

\begin{tabular}{lcc}
\hline Subgroup & $\begin{array}{c}\text { Technical success, } \mathrm{n}(\%) \\
\text { (macroscopically complete and en bloc) }\end{array}$ & $\begin{array}{c}\text { R0 resection, } \mathrm{n}(\%) \\
\text { (histologically confirmed complete resection) }\end{array}$ \\
\hline Indication & $5 / 6(83.3)$ & $5 / 6(83.3)$ \\
$\quad$ Non-lifting adenomas & $2 / 2(100)$ & $2 / 2(100)$ \\
Adenoma involving the appendiceal orifice & $2 / 3(66.6)$ & $2 / 3(66.6)$ \\
Adenocarcinomas & $5 / 6(83.3)$ & $5 / 6(83.3)$ \\
Subepithelial tumors & & $5 / 5(100)$ \\
Lesion size & $5 / 5(100)$ & $8 / 9(88.8)$ \\
$\leq 9$ mm & $8 / 9(88.8)$ & $1 / 3(33.3)$ \\
$10-20$ mm & $1 / 3(33.3)$ & $3 / 4(75)$ \\
$>20$ mm & $3 / 4(75)$ & $10 / 11(90.9)$ \\
Location of lesion & $10 / 11(90.9)$ & $1 / 2(50)$ \\
Distal colon ${ }^{*}$ & $1 / 2(50)$ & $6 / 8(75)$ \\
Proximal colon ${ }^{* *}$ & & $8 / 9(88.8)$ \\
Rectum & $6 / 8(75)$ & \\
Prior treatment & $8 / 9(88.8)$ & \\
No prior treatment & & \\
Previous endoscopic therapy & &
\end{tabular}

after initial polypectomy but lateral resection margins were 0.3 $\mathrm{mm}$. Final histological analysis revealed scar tissue. The second case was an adenocarcinoma of moderate differentiation and submucosal infiltration $<1000 \mu \mathrm{m}$. The tumor was located in the rectosigmoid transition and EFTR was not achieved because the lesion could not be drawn into the cap. The patient was treated surgically. The third case was a patient who was not a candidate for surgery because of cardiopulmonary comorbidities, treated with EFTR for an adenocarcinoma of moderate differentiation, restricted to submucosa. The resection was technically successful and histological evaluation revealed $\mathrm{T} 1$ adenocarcinoma with negative lateral and deep margins (R0 resection).

\section{Subgroup of subepithelial tumors $(n=6)$}

In the 6 patients with subepithelial tumors, technical success and R0 resection were achieved in 5 procedures (83.3\%). The median lesion size was 12.3 (range 5-30) $\mathrm{mm}$ and the resection sites were the following: cecum $(n=1)$, sigmoid $(n=3)$, rectosigmoid colon $(n=1)$, and rectum $(n=1)$. Final histological evaluation showed neuroendocrine tumor (NET) $(\mathrm{n}=5$, well differentiated-G1) and lipoma $(\mathrm{n}=1)$. One resection was macroscopically incomplete, probably because of the size of the target lesion $(30 \mathrm{~mm})$. The histological features of the resected specimen were compatible with a lipoma. All cases with histologically diagnosed NETs were discussed at oncology meetings for further assessment.

\section{Adverse events}

The overall complication rate was $17.6 \%$ (3/17) (Table 4). There were no complications associated with sedation. Postprocedural bleeding was observed in one patient $48 \mathrm{~h}$ after the
FTRD ${ }^{\circledR}$ procedure, but blood transfusion was not necessary. Reendoscopy revealed an ulcer with hematin around the clip arms and no further medical intervention was required. Another patient developed abdominal pain after successful resection of a residual adenoma in the sigmoid. Abdominal CT scan revealed no signs of perforation or local inflammation. The patient was treated with analgesics and pain gradually subsided in $24 \mathrm{~h}$. Both these patients were discharged after 4 days. The most serious complication was the development of acute appendicitis in a patient who had undergone EFTR for an adenoma involving the appendiceal orifice. The patient required laparoscopic appendectomy and stayed in hospital for 5 days.

\section{Follow up}

Nine of 17 patients underwent surveillance endoscopy. Two patients did not undergo follow up, since they had been treated surgically, and one patient diagnosed with a lipoma needed no surveillance. In the subgroup of difficult adenomas ( 7 of 8 cases of accomplished resection), 3-month follow up was available in 6 patients (1 patient refused surveillance). No residual lesions were observed endoscopically and biopsies taken from the resection site did not reveal pathological tissue. One-year follow up was available in 4 of these 6 patients and showed no evidence of recurrence. In the subgroup of patients with early adenocarcinomas ( 2 of 3 cases of accomplished resection), endoscopic surveillance was planned 1 year after curative EFTR (R0 resection), based on the European Society of Gastrointestinal Endoscopy and European Society of Digestive Oncology Guideline about endoscopic surveillance after endoscopic resection for colorectal cancer [14]. It is worthy of note that the cases included in our study were "low-risk" T1 adenocarcinomas. Follow up was available in both patients and found no evidence of residual tumor. In patients with subepithelial tumors ( $\mathrm{n}=5$ well-differentiated-G1 NETs), the oncology meetings 
Table 4 Adverse events

\begin{tabular}{|c|c|}
\hline Adverse event & No. \\
\hline Procedure-related adverse events, $\mathrm{n}(\%)$ & $3 / 17(17.6)$ \\
\hline Mild adverse events & - \\
\hline $\begin{array}{l}\text { Moderate adverse events } \\
\text { Minor bleeding } \\
\text { Major bleeding (transfusion needed) } \\
\text { Appendicitis conservatively treated } \\
\text { Post-polypectomy syndrome } \\
\text { Recurrent abdominal pain of unknown cause }\end{array}$ & $\begin{array}{l}1 \\
- \\
- \\
- \\
1\end{array}$ \\
\hline $\begin{array}{l}\text { Severe adverse events } \\
\text { Perforation } \\
\text { Acute appendicitis with requirement of } \\
\text { laparoscopic appendectomy } \\
\text { Enterocolonic fistula after EFTR of an } \\
\text { adenoma at appendiceal orifice }\end{array}$ & $\begin{array}{l}- \\
1 \\
-\end{array}$ \\
\hline
\end{tabular}

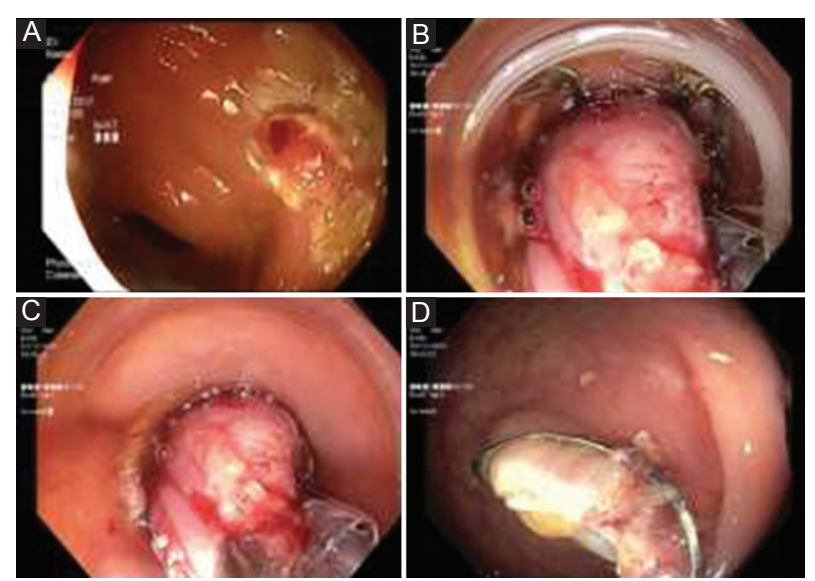

Figure 2 Key steps of EFTR. (A) The target lesion is marked circumferentially with the marking probe; (B) The lesion is drawn into the OTSC-loaded cap using FTRD ${ }^{\circledR}$ grasper; (C) The clip is released and the lesion is resected with the integrated snare; (D) Resection site after clip application

EFTR, endoscopic full-thickness resection; OTSC, over-the-scope clip; $F T R D^{\circledR}$, full-thickness resection device

of our centers recommended endoscopic surveillance 1-year after curative endoscopic removal (R0 resection) only in 1 patient. The remaining 4 NETs were completely resected, $<1 \mathrm{~cm}$ in size, grade 1 NETs. The oncology meetings recommended abdominal/pelvic CT or MRI along with blood tests and advised to discharge the patients from endoscopic follow up. Consequently, follow up was available in one case and there was no evidence of residual or recurrent lesion.

\section{Discussion}

The current study indicates that EFTR in appropriately selected patients is an adequately safe and efficacious endoscopic technique for the removal of colorectal lesions.
The most frequent indications among our participants were non-lifting adenomas and subepithelial tumors. In the total cohort, technical success and R0 resection rate was $82.3 \%$ (14 of 17 cases) which compares favorably to the results of previous studies (75-100\%) [5-12]. In the majority of previous reports $[5,6,9-12]$, the $\mathrm{R} 0$ resection rate in the total cohort was lower than the technical success rate. This may be explained by the fact that the mean diameter of the target lesions included in the above-mentioned studies was larger than the mean diameter of the lesions included in our study.

It is worth noting the features of the technically unsuccessful cases in our cohort. EFTR of a subepithelial tumor in the cecum, measuring $30 \mathrm{~mm}$, was accomplished but the resection was macroscopically incomplete. According to the literature, the recommended size of lesions prior to resection is $\leq 30 \mathrm{~mm}$ and for cases of severe scarring or inflammation 20-25 mm [9]. The maximum size of target lesions is a major limitation of EFTR, since the size of the FTRD ${ }^{\circledR}$ cap $(13 \times 23 \mathrm{~mm})$ does not accommodate lesions $>30 \mathrm{~mm}$ in diameter. Subgroup analysis in our study revealed that technical success and $\mathrm{R} 0$ resection rate was greater for lesions $\leq 20 \mathrm{~mm}$ than for those $>20 \mathrm{~mm}(\mathrm{P}=0.0429)$. Therefore, our results are in line with those of Schmidt et al [5], who also demonstrated a statistically significant difference in $\mathrm{R} 0$ resection rate between lesions $\leq 20 \mathrm{~mm}$ and lesions $>20 \mathrm{~mm}$. As already reported in previous studies, ESD represents the most reasonable endoscopic approach for rectal lesions $>30 \mathrm{~mm}$, especially for early adenocarcinomas, since EMR leads to piecemeal excision with an increased risk of incomplete resection [15-21]. Nonetheless, ESD for colonic lesions $>30 \mathrm{~mm}$ might be technically demanding or even not feasible. For these lesions, EMR combined with EFTR might be a promising approach, but evidence is lacking to date.

Furthermore, wall mobility is an important component for a complete EFTR, since the tissue volume that can be incorporated into the cap depends on the elasticity of the colonic wall at the resection site [6]. In our patients, two target lesions, located in the rectum and rectosigmoid transition, could not be sufficiently mobilized into the FTRD ${ }^{\circledR}$ cap and EFTR was not accomplished. We suppose that the location of these lesions contributed to the failure of EFTR.

The majority of our participants were diagnosed with nonlifting adenomas and subepithelial tumors. The R0 resection rate for non-lifting lesions was $83.3 \%$, compared to the $77.7 \%$ and 94.4\% reported in the two largest clinical studies of the FTRD ${ }^{\circledR}$ procedure $[5,6]$. Resection of non-lifting adenomas has been an important subject of study. Moss et al demonstrated that conventional endoscopic retreatment of residual and recurrent adenomas is highly effective, with success rates of $88.2 \%$ and $94.5 \%$, respectively [2]. Nonetheless, the patients in their study underwent a close follow-up protocol, necessitating repeat colonoscopies, and the majority of lesions were diminutive. ESD has been shown to be suitable for such adenomas, but the perforation rate has been reported to reach $14.7 \%[22,23]$. Moreover, ESD comprises an endoscopic technique with a long learning curve. Previous studies have suggested that the perforation risk and incomplete resection rate of EMR and ESD increase in the presence of fibrosis/scar or local recurrence, even in expert hands [24-26]. Based on the above-mentioned results and on the high rates of $\mathrm{R} 0$ resection reported in our study and in the 
literature, we believe that EFTR can be regarded as an efficacious intervention for the treatment of non-lifting adenomas. Finally, the $\mathrm{R} 0$ resection rate in the subgroup of subepithelial tumors was $83.3 \%$, consistent with the rates reported elsewhere $[5,6]$. Consequently, we suppose that EFTR can be considered as a valid alternative to surgical treatment for subepithelial lesions.

We included two patients with adenomas involving the appendiceal orifice. Technical success and $\mathrm{R} 0$ resection rate was $100 \%$. However, one patient developed acute appendicitis, due to the closure of the orifice by the OTSC, and required laparoscopic appendectomy. Previous studies have also demonstrated that $10 \%$ of patients treated with EFTR for the removal of adenomas involving the appendix developed acute appendicitis, with a subsequent rate of surgery of $2.9 \%[5,27]$. Considering the fact that acute appendicitis occurred in 1 of 2 cases, despite the small number of patients included $(n=2)$, we agree with Schmidt et al [5], who recommend EFTR only for lesions that would otherwise require surgical intervention, after providing thorough patient information.

In the subgroup of adenocarcinomas, the technical success and R0 resection rate was only $66.6 \%$, although the number of cases was limited $(n=3)$. The reason for the limited number of lesions included is that endoscopic excision of early adenocarcinomas remains a challenge. According to previous reports, endoscopic R0 resection is considered to be an adequate treatment for low-risk T1 adenocarcinomas [28,29]. Two recent retrospective clinical studies have recommended EFTR as an adequate alternative to surgical techniques for suspected T1 carcinomas $\leq 20 \mathrm{~mm}[6,7]$. Van der Spek et al performed EFTR with the FTRD ${ }^{\circledast}$ in 28 of 48 patients for suspected or confirmed low-risk T1 colorectal carcinomas based on endoscopic and histopathologic findings [7]. Surgical intervention was provided only when EFTR failed to achieve radical resection of the lesion. In contrast, Schmidt et al did not recommend EFTR as a therapeutic approach for suspected or known carcinomas, because of the low rates of curative resection [5]. The most recent study of EFTR for early colorectal cancer by Kuellmer et al [30] compared R0 resection rate between incompletely resected malignant polyps and non-lifting malignant lesions without prior treatment. Overall, $34 \%$ of patients underwent surgical resection owing to "high-risk" histological features, whereas $62 \%$ were followed endoscopically. The authors suggested that EFTR can be regarded as an effective alternative to surgical treatment for "low-risk" lesions and a valuable option for patients with "high-risk" lesions who are unfit for surgery. Nonetheless, the current policy in our departments is that surgical resection is the preferred treatment of adenocarcinomas, since it allows the radical removal of the neoplasm and of lymph nodes, providing exact disease staging. However, the fact that the FTRD ${ }^{\circledR}$ procedure does not necessitate tracheal intubation renders it feasible in special circumstances. Thus, we suggest EFTR as an alternative approach for elderly patients, for younger ones whose medical condition increases the risk of morbidity during surgical treatment, and for patients who refuse operation, weighing the risk of undetected lymphatic metastases. We also agree with Schmidt et al [5] that EFTR can be considered as a diagnostic tool, if indicated, for the exact determination of submucosal infiltration, lymphovascular invasion, and tumor differentiation.
Overall, adverse events occurred in $17.6 \%$. This rate appears to be slightly greater than the complication rates reported in previous studies (9.9-15.3\%) [5-8,12]. Clinical complications were observed in 3 patients. The majority of the adverse events were moderate and only one was severe. Post-procedural bleeding occurred in one case. Although no risk factor for intervention was identified, according to the risk factor-based algorithm suggested by Burgess et al for clinically significant delayed bleedings after wide-field EMR [31], the patient underwent a repeat colonoscopy. The bleeding was attributed to the eschar that had been sloughed off the resection site. The complication rate in our study remains comparable to rates reported elsewhere; we therefore also regard EFTR as an adequately safe endoscopic technique.

Malfunction of the FTRD ${ }^{\circledR}$ device occurred in one patient. After the turning of the OTSC hand wheel, the release ring was not released through the thread, although the OTSC had been successfully applied. The device was withdrawn and another endoscope was advanced to the adenoma ligated by the clip. The lesion was finally resected partially with a conventional snare. Clearly, the resection could not be fully completed because of the presence of the clip. However, the patient was re-endoscoped 2 months later, the clip remained in situ and the new biopsies obtained were negative for pathological tissue.

Overall, follow up was available in 9 of the 17 patients and no patient showed residual/recurrent lesions. The limitations of our study include the retrospective design and the limited number of the participants.

In conclusion, the results of this study compare favorably to data already reported in the literature. We recommend EFTR for the resection of lesions $\leq 20 \mathrm{~mm}$, non-lifting adenomas, and subepithelial tumors, but we believe that EFTR as primary therapy for low-risk T1 adenocarcinomas remains a field for further study. Large randomized studies comparing available surgical techniques with EFTR are required to better define the efficacy of EFTR and long-term outcomes.

\section{References}

1. Raju GS, Lum PJ, Ross WA, et al. Outcome of EMR as an alternative to surgery in patients with complex colon polyps. Gastrointest Endosc 2016;84:315-325.

2. Moss A, Williams SJ, Hourigan LF, et al. Long-term adenoma recurrence following wide-field endoscopic mucosal resection (WF-EMR) for advanced colonic mucosal neoplasia is infrequent: results and risk factors in 1000 cases from the Australian Colonic EMR (ACE) study. Gut 2015;64:57-65.

3. Oka S, Tanaka S, Saito Y, et al; Colorectal Endoscopic Resection Standardization Implementation Working Group of the Japanese Society for Cancer of the Colon and Rectum, Tokyo, Japan. Local recurrence after endoscopic resection for large colorectal neoplasia: a multicenter prospective study in Japan. Am J Gastroenterol 2015;110:697-707.

4. Burgess NG, Bourke MJ. Endoscopic resection of colorectal lesions: The narrowing divide between East and West. Dig Endosc 2016;28:296-305.

5. Schmidt A, Beyna T, Schumacher B, et al. Colonoscopic fullthickness resection using an over the-scope device: a prospective multicentre study in various indications. Gut 2018;67:1280-1289. 


\section{Summary Box}

\section{What is already known:}

- Endoscopic mucosal resection (EMR) and endoscopic submucosal dissection (ESD) are wellestablished endoscopic techniques for the removal of colorectal lesions

- Endoscopic full-thickness resection (EFTR) with the full-thickness resection device $\left(\mathrm{FTRD}^{\circledR}\right)$ is an invasive treatment for colorectal lesions not amenable to EMR and ESD

- Previous studies have shown that EFTR is feasible and efficacious for the resection of difficult adenomas (non-lifting and/or at difficult locations), early adenocarcinomas and subepithelial tumors

\section{What the new findings are:}

- This study presents the first Greek experience of the FTRD ${ }^{\circledR}$ procedure, assessing the efficacy and safety of EFTR

- The results of the current study are in line with data already reported in the literature and prove that EFTR in appropriately selected patients can be regarded as an adequately safe and efficacious endoscopic technique for the removal of colorectal lesions

6. Andrisani G, Soriani P, Manno M, et al. Colo-rectal endoscopic full-thickness resection (EFTR) with the over-the-scope device $\left(\mathrm{FTRD}^{\circledR}\right)$ : A multicenter Italian experience. Dig Liver Dis 2019;51:375-381.

7. van der Spek B, Haasnoot K, Meischl C, Heine D. Endoscopic full-thickness resection in the colorectum: a single-center case series evaluating indication, efficacy and safety. Endosc Int Open 2018;6:E1227-E1234.

8. Aepli P, Criblez D, Baumeler S, Borovicka J, Frei R. Endoscopic full thickness resection (EFTR) of colorectal neoplasms with the Full Thickness Resection Device (FTRD): Clinical experience from two tertiary referral centers in Switzerland. United European Gastroenterol J 2018;6:463-470.

9. Schmidt A, Bauerfeind P, Gubler C, Damm M, Bauder M, Caca K. Endoscopic full-thickness resection in the colorectum with a novel over-the-scope device: first experience. Endoscopy 2015;47:719-725.

10. Andrisani G, Pizzicannella M, Martino M, et al. Endoscopic fullthickness resection of superficial colorectal neoplasms using a new over-the-scope clip system: A single-centre study. Dig Liver Dis 2017;49:1009-1013.

11. Richter-Schrag HJ, Walker C, Thimme R, Fischer A. [Full thickness resection device (FTRD). Experience and outcome for benign neoplasms of the rectum and colon]. Chirurg 2016;87:316-325.

12. Vitali F, Naegel A, Siebler J, Neurath MF, Rath T. Endoscopic fullthickness resection with an over-the-scope clip device (FTRD) in the colorectum: results from a university tertiary referral center. Endosc Int Open 2018;6:E98-E103.

13. Cotton PB, Eisen GM, Aabakken L, et al. A lexicon for endoscopic adverse events: report of an ASGE workshop. Gastrointest Endosc 2010;71:446-454.

14. Hassan C, Wysocki PT, Fuccio L, et al. Endoscopic surveillance after surgical or endoscopic resection for colorectal cancer: European Society of Gastrointestinal Endoscopy (ESGE) and European Society of Digestive Oncology (ESDO) Guideline. Endoscopy 2019;51:266-277.

15. Saitoh Y, Inaba Y, Sasaki T, Sugiyama R, Sukegawa R, Fujiya M. Management of colorectal T1 carcinoma treated by endoscopic resection. Dig Endosc 2016;28:324-329.

16. Sajid MS, Farag S, Leung P, Sains P, Miles WF, Baig MK. Systematic review and meta-analysis of published trials comparing the effectiveness of transanal endoscopic microsurgery and radical resection in the management of early rectal cancer. Colorectal Dis 2014;16:2-14.

17. Kidane B, Chadi SA, Kanters S, Colquhoun PH, Ott MC. Local resection compared with radical resection in the treatment of T1N0M0 rectal adenocarcinoma: a systematic review and metaanalysis. Dis Colon Rectum 2015;58:122-140.

18. Bartel MJ, Brahmbhatt BS, Wallace MB. Management of colorectal T1 carcinoma treated by endoscopic resection from the Western perspective. Dig Endosc 2016;28:330-341.

19. Guerrieri M, Baldarelli M, de Sanctis A, Campagnacci R, Rimini M, Lezoche E. Treatment of rectal adenomas by transanal endoscopic microsurgery: 15 years' experience. Surg Endosc 2010;24:445-449.

20. Lee L, Burke JP, deBeche-Adams T, et al. Transanal minimally invasive surgery for local excision of benign and malignant rectal neoplasia: outcomes from 200 consecutive cases with midterm follow up. Ann Surg 2018;267:910-916.

21. Probst A, Ebigbo A, Märkl B, et al. Endoscopic submucosal dissection for early rectal neoplasia: experience from a European center. Endoscopy 2017;49:222-232.

22. Kuroki Y, Hoteya S, Mitani T, et al. Endoscopic submucosal dissection for residual/locally recurrent lesions after endoscopic therapy for colorectal tumors. J Gastroenterol Hepatol 2010; 25:1747-1753.

23. Sakamoto T, Saito Y, Matsuda T, Fukunaga S, Nakajima T, Fujii T. Treatment strategy for recurrent or residual colorectal tumors after endoscopic resection. Surg Endosc 2011;25:255-260.

24. Isomoto $\mathrm{H}$, Nishiyama $\mathrm{H}$, Yamaguchi $\mathrm{N}$, et al. Clinicopathological factors associated with clinical outcomes of endoscopic submucosal dissection for colorectal epithelial neoplasms. Endoscopy 2009;41:679-683.

25. Hori K, Uraoka T, Harada K, et al. Predictive factors for technically difficult endoscopic submucosal dissection in the colorectum. Endoscopy 2014;46:862-870.

26. Saito Y, Uraoka T, Yamaguchi Y, et al. A prospective, multicenter study of 1111 colorectal endoscopic submucosal dissections (with video). Gastrointest Endosc 2010;72:1217-1225.

27. Valli PV, Mertens J, Bauerfeind P. Safe and successful resection of difficult GI lesions using a novel single-step full-thickness resection device $\left(\right.$ FTRD $^{\circledR}$ ). Surg Endosc 2018;32:289-299.

28. Labianca R, Nordlinger B, Beretta GD, et al. Early colon cancer: ESMO clinical practice guidelines for diagnosis, treatment and follow-up. Ann Oncol 2013;24(Suppl 6):vi64-vi72.

29. Backes Y, de Vos Tot Nederveen Cappel WH, van Bergeijk J, et al. Risk for incomplete resection after macroscopic radical endoscopic resection of T1 colorectal cancer: A multicenter cohort study. Am J Gastroenterol 2017;112:785-796.

30. Kuellmer A, Mueller J, Caca K, et al. Endoscopic full-thickness resection for early colorectal cancer. Gastrointest Endosc 2019;89:1180-1189.e1.

31. Burgess NG, Williams SJ, Hourigan LF, et al. A management algorithm based on delayed bleeding after wide-field endoscopic mucosal resection of large colonic lesions. Clin Gastroenterol Hepatol 2014;12:1525-1533. 